training research workers, aeronautical engineers and other technicians are under continuous review by the Technical Personnel Committee. It is agreed that men with postgraduate research and similar qualifications should not be allowed to enter the Forces, except for special commissioned posts, for example, operational research. The allocation and deferment arrangements of the Ministry of Labour are considered to provide ample safeguards for this purpose. A professional engineering or scientific qualification is, however, essential for many commissioned posts in the Fighting Services, and in view of the recommendations of Sir William Beveridge's Committee on the Use of Skilled Men in the Services, it has been recognized that a substantial proportion of technical officers in the Services in charge of maintenance and repair of equipment should possess technical qualifications of a university degree or professional standard together with extensive practical experience. But the numbers thus made available were insufficient. It has therefore been necessary to allocate a substantial proportion of the university output to the Services, and also to withdraw experienced men from industry; many of the latter have been volunteers, and the Ministry is concerned lest the Select Committee's observations should be misunderstood, with unfortunate effect on such volunteering.

Steps have also been taken to increase the supply of men graduating in technical subjects by means of the State bursaries, the intensive Higher National Certificate and the Engineering Cadetship schemes. Courses at universities have keen shortened to a maximum of two years and three months (two years and nine months in Scotland), and by these measures the output has been substantially increased since 1941 and will reach a peak in 1944. In view of these shortened courses, the Technical Personnel Committee considers that specialized pre-graduate aeronautical courses could be extended only at the expense of fundamental engineering training. The needs of the industry during the War can lest be met by the continuation of the existing pre-graduate engineering courses. Apart from a small number of the most promising men who can benefit by a special postgraduate course in aeronautics, graduates should proceed at once to aircraft establishments or firms where they can specialize and pull their weight at the earliest possible moment.

\section{Health in Industry}

A MaJor problem brought to the fore during this War has been to bridge the gulf between scientific knowledge and its application. The Industrial Health Research Board has, during the last twenty-five years, published more than eighty reports on industrial conditions in relation to the health and wellbeing of the workers. Unfortunately, the necessity for publishing all the data, so that other workers in this field could know what exactly was the evidence on which the conclusions were based, rendered them of little use to those concerned with organizing industry. To remedy this, pamphlets are to be issued giving the conclusions in more general form, and No. 1, called "Ventilation and Heating; Lighting and Seeing", has just been published (H.M. Stationery Office, price $3 d$ ).

The first part deals with the need for ventilation, the amount of fresh air required, air movement and its problems, some effects of high temperatures, and the complications due to the black-out. The second part gives the principles of good factory lighting, how to measure light, and how the factory regulations should be interpreted, so as to ensure a good general appearance of cheerfulness as well as sulficient light to see the work. Good lighting alone cannot, however, prevent eye-strain for certain kinds of work, so there is a simple account of the working of the muscles of the eyes and of the relief to be secured by the use of special spectacles. There are illustrations showing different systems of artificial lighting, examples of undesirable as well as desirable systems. One undesirable method is called "Glare and Gloom". The pamphlet contains much useful scientific information expressed in readable form.

\section{Measurements at Radio Frequencies}

Following the annual general meeting of the Radio Society of Great Britain held on Decemker 18, Dr. R. L. Smith-Rose gave a lecture on "Measurements in Radio Experimental Work". After referring to the part played by amateur observers and experimenters in sciences such as astronomy and meteorology as well as in radio, Dr. Smith-Rose emphasized the importance of carrying out quantitative measurements in an orderly and systematic manner. A brief review then followed of the present position in the national laboratories of Great Britain and the United States, of the absolute electrical standards of current, inductance and resistance, and of the practical working standards which are derived therefrom. Frequency is one of the absolute electrical standards common to all branches of electrical engineering, from the low frequencies of the power engineer to the highest used in the modern applications of radio technique : and it is noteworthy that the precision of frequency measurement far exceeds that attainable in the determination of any other radio or electrical quality. With the possible exceptions of current and voltage, most measurements at radio frequencies, such as impedance, resistance and reactance, are made by reference to direct current or low-frequency standards. The lecture concluded with a brief description of some investigations illustrating the application of certain types of measurements at radio frequencies to the determination of the mode of transmission of electric waves along the earth's surface.

\section{Determination of Polar Diagrams of Radio Antennæ}

AN article by H. Paul Williams (Elec. Comm., 21, No. 2 ; 1943) describes a machine which enables one to determine a polar diagram in a fraction of the time required by direct calculation. A computation which ordinarily would take a whole day can be performed in fifteen minutes on the machine. In its present version, it will calculate the polar diagram given by as many as five antennæ. These may be situated anywhere within a circle of four wavelengths diameter, while the currents in the antennæe may have any relative phases and magnitudes. The exploring angle is read off from a dial marked in degrees, and the corresponding relative amplitude is shown directly on a voltmeter. As few or as many readings as one likes can ke taken, and also one may turn the handle backwards to a previous value if required.

With such a machine there is an appreciable reduction in the possibilities of errors-a feature quite as important as the saving of time. It is now also practicable to consider a large number of variations in a design the working out of which would take a prohibitive time without such a machine. Although 